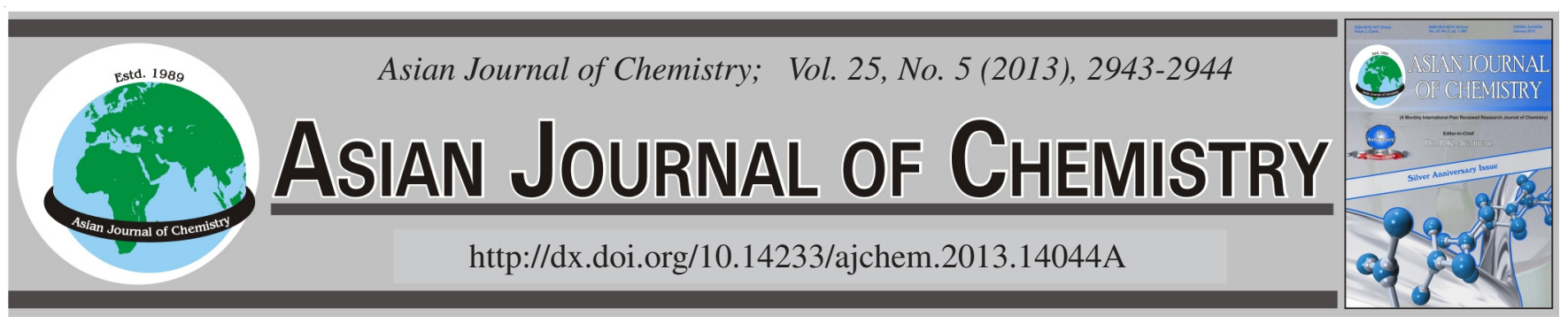

NOTE

\title{
Improving the Dispersity of Nano-silica from Rice Hull Ash in Organic Solvents by a New Surface Modification Method
}

\author{
YULIN Li
}

College of Life Science, Hubei Normal University, 11 Cihu Road, Huangshi 435002, P.R. China

*Corresponding author: Tel: +86 135 45508639; E-mail: liyulin7226@163.com

(Received: 10 May 2012;

Accepted: 30 November 2012)

AJC-12491

Different surface modification methods improving the dispersity of nano-silica from rice hull ash in organic solvents by $\gamma$ -
methacryloxypropyltrimethoxy silane in anhydrous alcohol solution were investigated. The optimum modification method was that nano-
silica powders were chemically modified by $\gamma$-methacryloxypropyltrimethoxy silane in anhydrous alcohol solution and $\gamma-$
methacryloxypropyltrimethoxy silane in anhydrous alcohol solution was dropwise added at $3 \mathrm{~mL} / \mathrm{min}$. Dibutyl phthalate absorption
number of the optimum modified nano-silica was $3.2 \mathrm{~cm}^{3} / \mathrm{g}$.
Key Words: Surface modification, Improving, Dispersity, Nano-silica, Organic solvent.

ᄂ - - - - - - - - - - - - - - - - - - - - - - - - - - - -

Improving the dispersity of nano-silica in organic solvents had caused intensively interesting because nano-silica welldispersed in organic solvents could be extensively used in rubber, paint and plastic industries ${ }^{1-7}$. In previous investigations, silica was modified to improve its dispersity in organic solvents by vinyltriethoxysilane ${ }^{8}$, oleic acid ${ }^{9}$, titanate ${ }^{10}$ and aminopropyltriethoxysilane ${ }^{11}$. These modified products were not well dispersed in organic solvents yet ${ }^{8-11}$. Moreover, these modifiers had two disadvantages: (1) once encountered a polar medium, these modifiers were easy to be separated from the surface of silica $^{8,9}$; (2) their unsaturated bonds could not react with the surface -OH groups of silica effectively ${ }^{10,11}$. Therefore silane coupling agent was considered as a new modifier. Li et al. ${ }^{12}$ modified nano-silica gel by silane coupling agent and silane coupling agent was dropwise added. It is found that silane coupling agent could improve the dispersity of nano-silica in organic solvents and $\gamma$-methacryloxypropyltrimethoxy silane was the best among all used silane coupling agents ${ }^{12}$. These researchers used a modification method respectively and did not demonstrate that which method was optimum. The objective of this study was to improve the dispersity of nano-silica in organic solvents by a new surface modification method. Dibutyl phthalate absorption number was used as an index of evaluating the modification effect.

$\gamma$-Methacryloxypropyltrimethoxy silane was purchased from the Nanjing Crompton Shuguang Organosilicon Company in China. Other reagents were analytical grade.
$\gamma$-Methacryloxypropyltrimethoxy silane anhydrous alcohol solution $(0.5 \mathrm{~mol} / \mathrm{L}, 80 \mathrm{~mL})$ was added in nano-silica gel in the flask using the following three methods respectively: (1) It was dropwise added at $3 \mathrm{~mL} / \mathrm{min}$ by a constant flow pump $^{12}$; (2) Half of $\gamma$-methacryloxypropyltrimethoxy silane anhydrous alcohol solution was overall added at first and the residuum was dropwise added at $3 \mathrm{~mL} / \mathrm{min}$ by a constant flow pump; (3) It was overall added. The remaining treating methods were the same as described above. Three samples from modified nano-silica gel were obtained.

Nano-silica powders $(3 \mathrm{~g})$ and deionized water $(30 \mathrm{~mL})$ were added in a $50-\mathrm{mL}$ flask, heated at $80{ }^{\circ} \mathrm{C}$ in water bath with stirring at $260 \mathrm{rpm}$ and condensed. Adding methods of $\gamma$ methacryloxypropyltrimethoxy silane in anhydrous alcohol solution $(0.5 \mathrm{~mol} / \mathrm{L}, 80 \mathrm{~mL})$ were the same as described above. The reactions were lasted for $90 \mathrm{~min}$. The remaining treating methods were the same as described above. Three samples from modified nano-silica powders were obtained.

Different modified nano-silica samples ( $1 \mathrm{~g}$, respectively) was dried at $105^{\circ} \mathrm{C}$ for $1.5 \mathrm{~h}$ and placed on a glass board (170 $\times 140 \mathrm{~mm}$ ) and used to determine dibutyl phthalate absorption number.

Statistical analysis was carried out using ORIGIN 7.5 (OriginLab Inc., USA).

Dibutyl phthalate absorption number is an important property of silica. The dispersity of nano-silica in organic solvents was greatly related to dibutyl phthalate absorption number ${ }^{2,12}$. 
So dibutyl phthalate absorption number was used as an index of evaluating the modification effect in this study. Dibutyl phthalate absorption number of different modified nano-silica was listed in Table-1. The optimum method was that nanosilica powders were chemically modified by $\gamma$-methacryloxypropyltrimethoxy silane in anhydrous alcohol solution and $\gamma$-methacryloxypropyltrimethoxy silane in anhydrous alcohol solution was dropwise added at $3 \mathrm{~mL} / \mathrm{min}$. It was due to the reason that there was no steric hindrance on the surface of nano-silica powder and nano-silica powder and $\gamma$-methacryloxypropyltrimethoxy silane could react freely and adequately very much. When nano-silica gel was chemically modified by $\gamma$-methacryloxypropyltrimethoxy silane in anhydrous alcohol solution and $\gamma$-methacryloxypropyltrimethoxy silane anhydrous alcohol solution was overall added, dibutyl phthalate absorption number of the sample was the second among these samples. It was due to that the reaction between sodium silicate solution and $\gamma$-methacryloxypropyltrimethoxy silane greatly promoted the modification reaction. When nano-silica powder was chemically modified by $\gamma$-methacryloxy-propyltrimethoxy silane anhydrous alcohol solution and half of $\gamma$-methacryloxypropyltrimethoxy silane in anhydrous alcohol solution was overall added at first and the residuum was dropwise added at $3 \mathrm{~mL} / \mathrm{min}$, dibutyl phthalate absorption number of the sample was the third among these samples. It was due to that there was less steric hindrance on the surface of nano-silica powder and nano-silica powder and $\gamma$-methacryloxypropyltrimethoxy silane could react freely and adequately. When nano-silica gel was chemically modified by $\gamma$-methacryloxypropyltrimethoxy silane anhydrous alcohol solution and half of $\gamma$-methacryloxypropyltrimethoxy silane anhydrous alcohol solution was overall added at first and the residuum was dropwise added at $3 \mathrm{~mL} / \mathrm{min}$, dibutyl phthalate absorption number of the sample was the forth among these samples. It was due to that the reaction between sodium silicate solution and $\gamma$-methacryloxypropyltrimethoxy silane promoted the modification reaction. When nano-silica powder was chemically modified by $\gamma$-methacryloxypropyl-trimethoxy silane anhydrous alcohol solution and $\gamma$-methacryloxypropyltrimethoxy silane anhydrous alcohol solution was overall added, dibutyl phthalate absorption number of the sample was the fifth among these samples. It was due to that there was more steric hindrance on the surface of nano-silica powder and nano-silica powder and $\gamma$-methacryloxypropyltrimethoxy silane could not react freely and adequately. When nano-silica gel was chemically modified by $\gamma$-methacryloxypropyltrimethoxy silane anhydrous alcohol solution and $\gamma$-methacryloxypropyltrimethoxy silane anhydrous alcohol solution was dropwise added at $3 \mathrm{~mL} / \mathrm{min}$, dibutyl phthalate absorption number of the sample was the sixth among these samples. It was due to that $\gamma$-methacryloxypropyltrimethoxy silane could not be dispersed in the viscous nano-silica gel and the modification reaction only happened in the local place. According to the variance, the effect of the modification object on the modification effect was greater than adding method of $\gamma$-methacryloxypropyltrimethoxy silane anhydrous alcohol solution. It was due to that the dispersity of nano-silica in organic solvents was mainly depended on its structure. Other researchers did not use dibutyl phthalate absorption number as an index of evaluating the modification effect.

\begin{tabular}{|c|c|c|c|}
\hline \multicolumn{4}{|c|}{$\begin{array}{c}\text { TABLE-1 } \\
\text { ORTHOGONAL ARRAY* (DBP ABSORPTION } \\
\left.\text { NUMBER OF NANO-SILICA: } 2.0 \mathrm{~cm}^{3} / \mathrm{g}\right)\end{array}$} \\
\hline Sample & A & $\mathrm{B}$ & DBP absorption number $\left(\mathrm{cm}^{3} / \mathrm{g}\right)$ \\
\hline 1 & 1 & 1 & $2.6 \pm 0.1^{\mathrm{a}}$ \\
\hline 2 & 1 & 2 & $2.9 \pm 0.1^{b}$ \\
\hline 3 & 1 & 3 & $3.0 \pm 0.1^{\mathrm{c}}$ \\
\hline 4 & 2 & 1 & $3.2 \pm 0.1^{\mathrm{d}}$ \\
\hline 5 & 2 & 2 & $3.1 \pm 0.1^{\mathrm{e}}$ \\
\hline 6 & 2 & 3 & $2.8 \pm 0.1^{\mathrm{f}}$ \\
\hline $\mathrm{K} 1(\%)$ & 8.5 & 5.8 & \\
\hline $\mathrm{K} 2(\%)$ & 9.1 & 6.0 & \\
\hline K3 (\%) & & 5.8 & \\
\hline Variance $(\%)$ & 0.6 & 0.2 & \\
\hline \multicolumn{4}{|c|}{$\begin{array}{l}\text { *Values are means } \pm \text { SD }(n=3) \text {. Values followed by the different } \\
\text { superscript letters in the same column are significantly different }(P \leq \\
0.05)\end{array}$} \\
\hline
\end{tabular}

\section{Conclusion}

The optimum modification method was that nano-silica powder was chemically modified by $\gamma$-methacryloxypropyltrimethoxy silane anhydrous alcohol solution and $\gamma$-methacryloxypropyltrimethoxy silane anhydrous alcohol solution was dropwise added at $3 \mathrm{~mL} / \mathrm{min}$. dibutyl phthalate absorption number of the optimum modified nano-silica was $3.2 \mathrm{~cm}^{3} / \mathrm{g}$. These results suggested that the selected optimum modification method was effective.

\section{ACKNOWLEDGEMENTS}

This study was financially supported by Earmarked Fund for Modern Agro-industry Technology Research System, Innovation Project of Education Ministry (No. IRT0627) and Food Processing Technology Research (No. 2006BAD05A10).

\section{REFERENCES}

1. G.-M. Gao, H.-F. Zou, S.-C. Gan, Z.-J. Liu, B.-C. An, J.-J. Xu and G.H. Li, Powder Technol., 191, 47 (2009).

2. S.D. Bhagat and A.V. Rao, Appl. Surf. Sci., 252, 4289 (2006).

3. F. Shi, L.J. Wang and J.X. Liu, Mater. Lett., 60, 3718 (2006).

4. L. Zhao, J.G. Yu, B. Cheng and C.Z. Yu, J. Non-cryst. Solid, 351, 3593 (2005).

5. L. Zhao and J.G. Yu, J. Colloid Interf. Sci., 304, 84 (2006).

6. Y.L. Li, Z.X. Chen, X.X. Li and H.W. Zeng, Asian J. Chem., 23, 893 (2011).

2. Y.L. Li, Z.X. Chen, X.X. Li and H.W. Zeng, Asian J. Chem., 23, 1822 (2011).

8. H.L. Su, J.-M. Hsu, J.-P. Pan and C.-S. Chern, J. Appl. Polym. Sci., 103, 3600 (2007).

9. Z.W. Li and Y.F. Zhu, Appl. Surf. Sci., 211, 315 (2003).

10. A. Voelkel and T. and Grzeskowiak, Chromatographia, 51, 608 (2000).

11. C. Takai, M. Fuji and M. Takahashi, Colloids. Surf. A, 292, 79 (2007).

12. X.H. Li, Z. Cao, Z.J. Zhang and H.X. Dang, Appl. Surf. Sci., 252, 7856 (2006). 